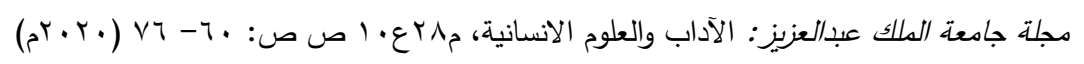

DOI:10.4197/Art.28-10.3

\title{
"نكاح (زواج) المشاركة في اليمن القديم \\ دراسة تحليلية"
}

\section{د. نجوى محمد إكرام}

$$
\text { أستاذ مشارك التاريخ القديم }
$$

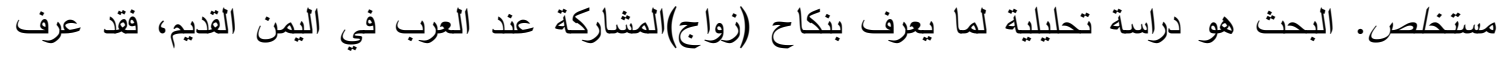
العرب في العصور القديمة حالات زواج غير عادية ومنها نكاح (زواج) المشاركة (Polyandry Marriage) وهو تعدد الأزواج، أي اشتراك عدة رجال في الزواج من امرأة واحدة. البحث يلقي الضوء على اختلاف الآراء بين الباحثين حول هذا الزواج ما بين من يرى أنه كان معردأ معروفاً وموجوداً عند العرب القدامى، ومن يرى عكس ذلك. الباحث أورد بضع من النقوش السبئية للتأكيد على وجود حالات من زواج (نكاح) المشاركة، أو تعدد الأزواج،

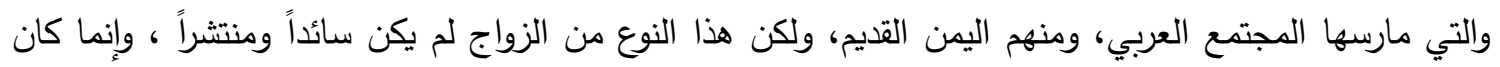
محدوداً ونادراً. كان الزواج المألوف بين العرب القدامى في شبه الجزيرة العربية، هو الزواج التقليدي (الشرعي)(')، أي الزواج القائم

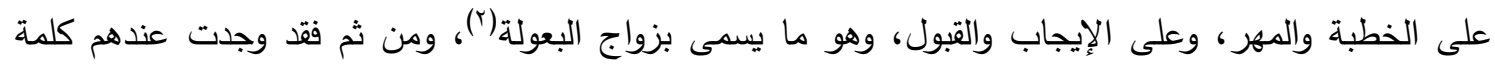

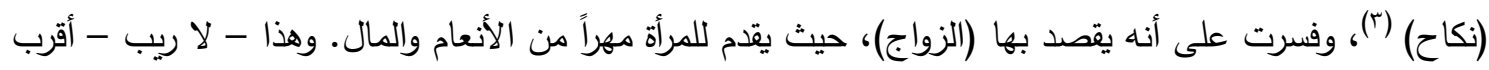

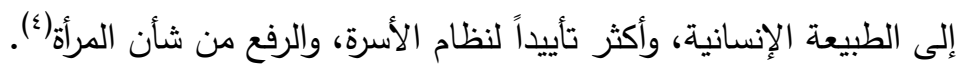

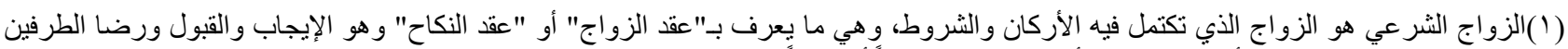

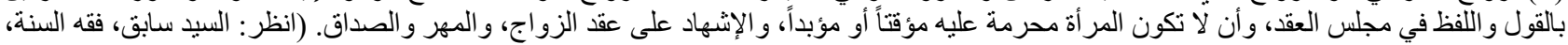

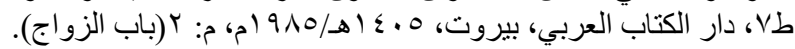

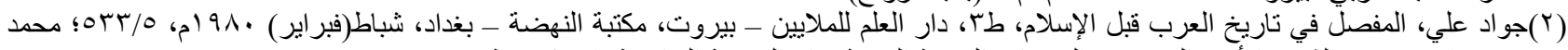

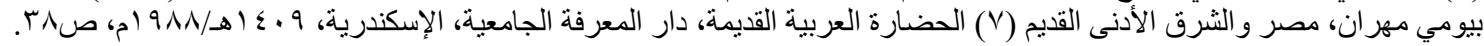

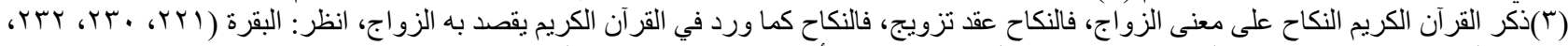

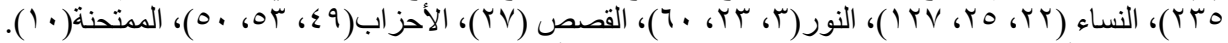

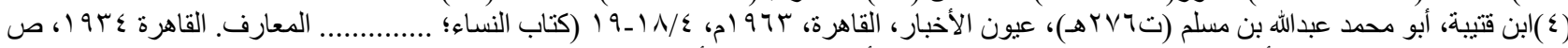

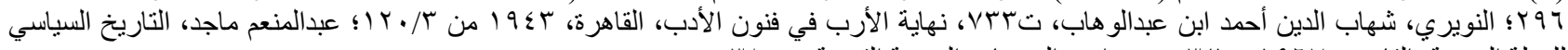


ذات مرة كان جميع الأخوة في السوق ثم ذهب أحدهم وشاهد عصاه أمام الباب واعتقد أن أحدهم (أحد إخوته) موجود معها، لكنه تذكر أنه ترك

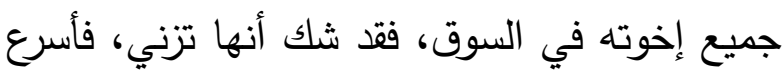
إلى والده وقاده إلى البيت، لكن تبين أنه قد اتهح

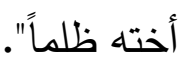

يترجم الثيبة بأنها: "فأدينت بجريمة الزنا ولقيت حتفها"(r)، بدلاً من "لكن تبين أنه قد إتهم أخته

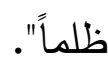

وهو بذلك يخالف ترجمة المبروك عن النص

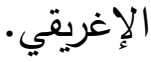
ينظر هارتمان (Hartmann) بعين الثك فيما يرويه سترابو، بل يميل إلى إنكار هذا الزواج، حيث يرى

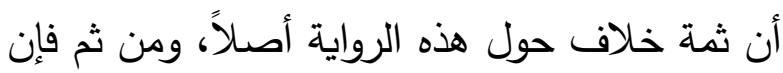

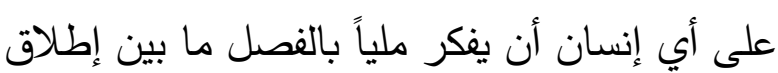

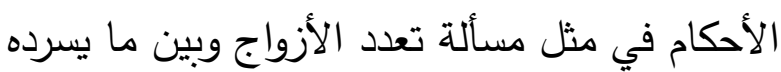

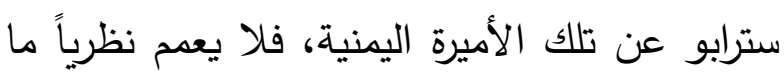
تهدف إليه الرواية(؟).

ذهب بعض الباحثين إلى اشتراك الإخوة في زوجة

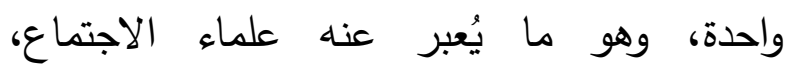

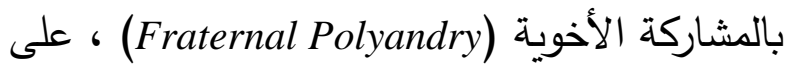
نحو ما أشار إليه سترابو وهو زواج يعد مرحلة

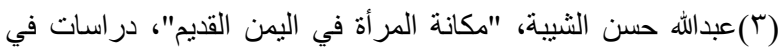

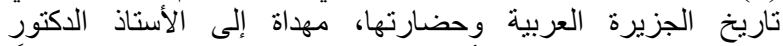

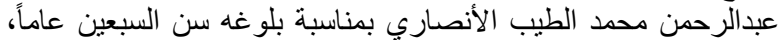

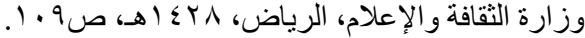

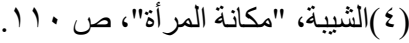

Hartmann, M., Der Islamische Orient, Bd, ii. Die Arabische frage, Lepizie, 1909, P.199.
وأما أنواع النكاح عند العرب القدامى - غير نكاح

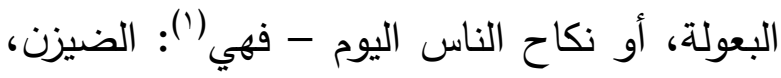

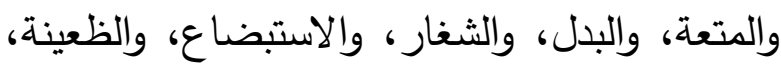
والإماء، ولكن هناك نوع من النكاح، هو نكاح

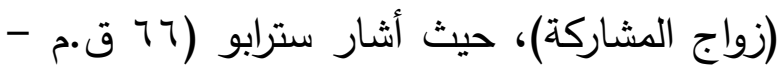
ع זم) إليه في النص التالي (r) "كما تكون لهم جميعاً زوجة واحدة، والذي في ليصل

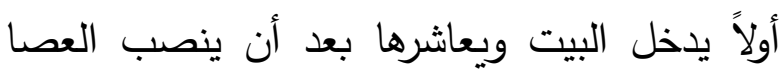
(العكاز) أمام البيت لأنه كان من العادة أن يشاهد كل واحد وهو يحمل العصا، وتقضي (المرأة) الليلة مع الأكبر سناً. لذلك فإنهم جميعاً كانوا أخوة...". ويضيف سترابو أنه: "كان لأحد الملوك ابنة جميلة جداً ولها خمسة عشر الهر أخاً، وكانوا جميعاً عشاقاً لها وكانوا يعاشرونها لهان الها باستمرار الواحد بعد الآخر، لكنها بعد أن تعبت وانتان

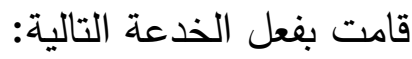
صنعت عُصِيّاً تشبه عصى أولئك (إخوتها) وعندما يخرج أحدهم من عندها تضع العصا التي تشبه عصاه أمام الباب، وبعد ذلك غيرها وهكذا، وقد ساعدها في ذلك أنه لم يصادف أن اقترب أحدهم ووجد العصا التي تشبه عصاه أمام الباب، لكن

(1) عن أنوع الزواجـ، تفصيلياً، أنظر : مهران، الحضارة العربية القديمة،

(2) Strabo, The Geography of Strabo, trans by:

H.L. Jones, London, 1966, XVI, 4, eh.25.

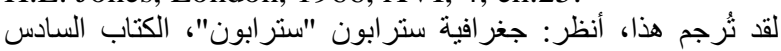

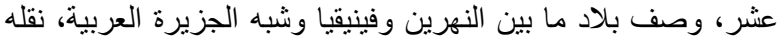

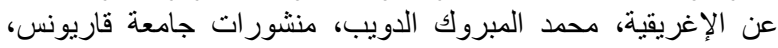

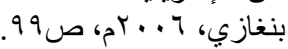


معكوسة لزواج الأخوة مشتركاً في زوجة واحدة، فلم يكن هناك رادع قانوني يمنع الرجل من التزوج من الأخوات في زمن واحد ومن الجمع بينهن في صعيد الزوجية، وفي بعولة رجل واحد(). وهو في جملة

أنواع الزواج الذي نهى عنه الإسلام (؟). في حقيقة الأمر إن زواج المشاركة (Polyandry) يسبب مشكلة خطيرة في تعيين أبوة الأبناء ، ومن ثم فهم - في غالب الأحايين - ينتسبون إلى الأمهات، كما أنه في نفس الوقت زواج داخلي بين أفراد العشيرة الواحدة، فضلاً عن ارتهانه بارتحال أهل المرأة وانتقالهم من مكان إلى آخر (v). هنالك من يرى أن بعض علماء الاجتماع المحدثين قد صدقوا فرية سترابو هذه، ومن ثم فقد عللوا تعدد الأزواج للزوج الواحدة بقلة النساء عن الرجال بسبب

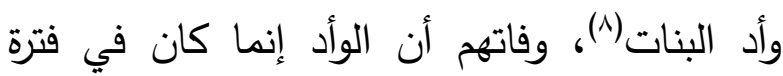
معينة - وفي قبائل معينة ليس بينها القبائل اليمنية على أي حال(")، حيث نقش به به نص قانون اجتماعي لمدينة مطرة، جاء فيه:

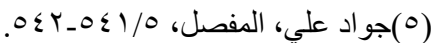

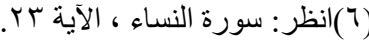

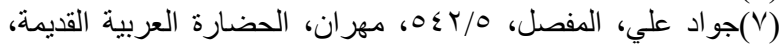
صن

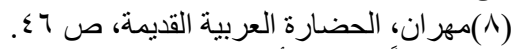

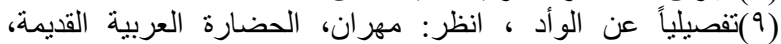

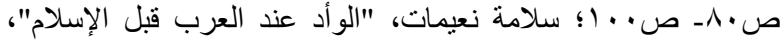

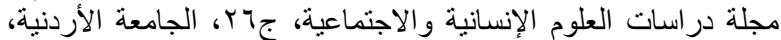

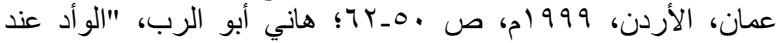

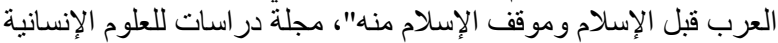

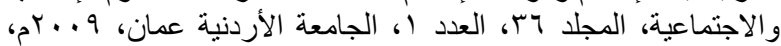

وسطى بين تعدد الأزواج البدائي(Polyandry)(') الذي لم يكن مقيداً بقيود، وبين الزواج الذي أباحته لئه الأديان السماوية وهو زواج البعولة الذي كان شائعاً بين غالبية العرب في عصر ما قبيل الإسلام، وعند ظهور الإسلام، وليس مستبعداً أن يكون سترابو قد فيل

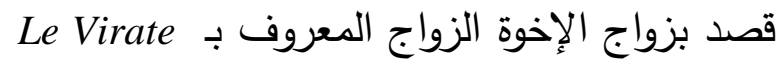

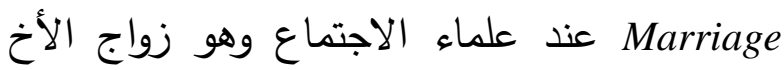
زوجة أخيه بعد وفاته، وهو زواج نشأ على رأي

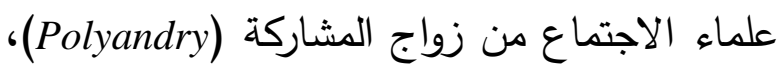
وهو معروف عند العرب وعند العبرانيين والحبش وبلاد التبت، وأن العرب مروا بمرحلة تعدد الأزواج هذه قبل أن يتجاوزوها إلى الانفراد بزوجاتهم (؟). يذهب الباحثون إلى آراء مختلفة حول أصل هذا لها

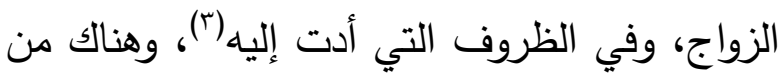

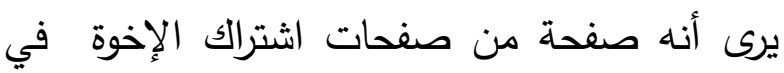
زوج واحدة، واشتراك الأخوة في تزوج الأخوات، وهو

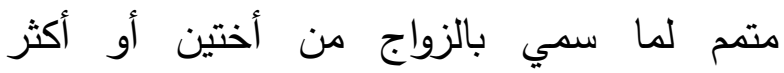
(Sororate) عصر ما قبل الإسلام، وهذا الزواج هو صورة هورة

لفظة يونانية مكونة من مقطعين (Polyandros)polyandry(') (Poly) المتعددون"، ويراد بها المرأة ذات الأزواج .(النظر: حرف (P) (Webster Dictionary جو اد علي، المفصل ، 1/0 إن، محمد محمود جمعة، النظم الاجتماعية و السباسية عند قدماء العرب و الأمم السامية،

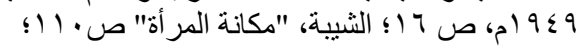

Encyclopaedia of Religion and Ethics, Vol, 8, P. 467; Robertson Smith, W., Kingship and Marriage in Early Arabias, London, 1885, P. 159.

(广T) جو اد علي، المفصل، 0 (T)

(4) Encyclopaedia Britannica, 21, p.21. 
مدينة مطرة - كما سبق - يمنع قتل البنات(؟).

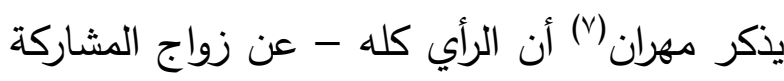
- إنما يعتمد على رواية سترابو، ويرى أنها ليست

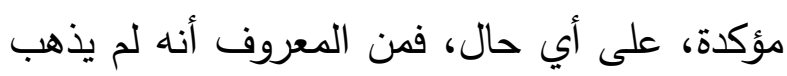

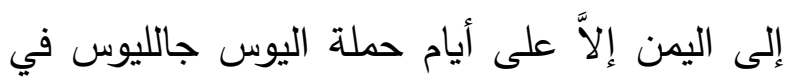

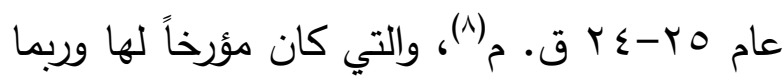

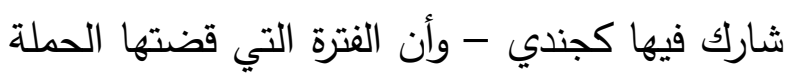
في اليمن ليست بكافية ليتعرف الرجل على القوم

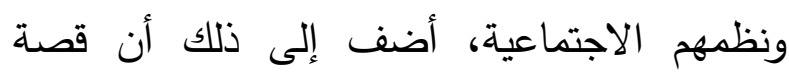
وضع العصا على باب الخيمة(9)، تزعزع الثقة في الرواية كلها، فما كان اليمنيون وقت ذلك يسكاب ليكنون

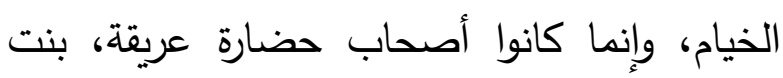
القصور والسدود والمعابد، وسبقت أيام الحملة فيها

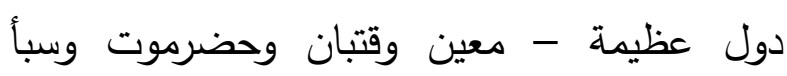
وأوسان وغيرها - ولهذا كله فأغلب الظن أن وفضن معلومات سترابو غير صحيحة، أو على الأقل أن قصتّه هذه إنما تصور حالة شاذة سمع بها - أو أو الو

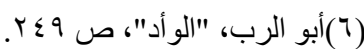

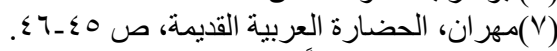

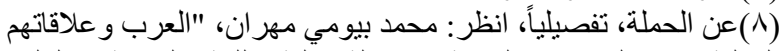

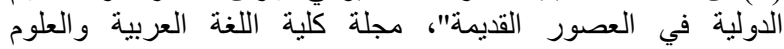

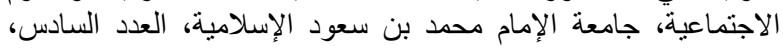

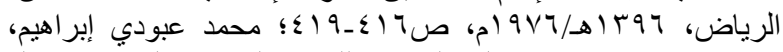

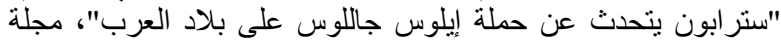

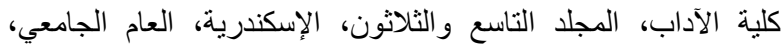

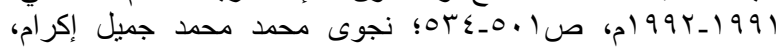

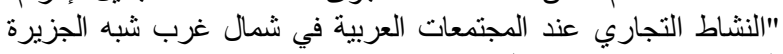

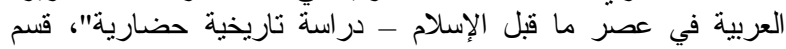

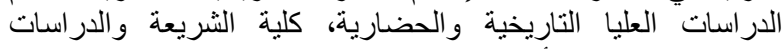

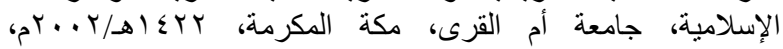

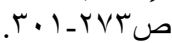
(9)لقد ترجم الذويب بأنه (البيت) وليس الخيمة، لأنه ترجم عن النص النص

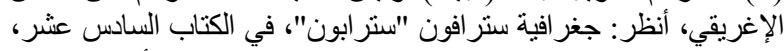

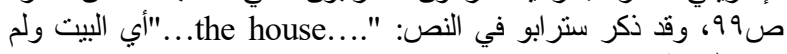

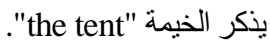

"لايحق شرعاً وأد بنات المدينة من قِبل أفراد

\section{الثعب شعب مدينة مطرة"(')}

ويرى ابن حبيب أن الطلس كانوا لا يئدون بناتهه، مطرة

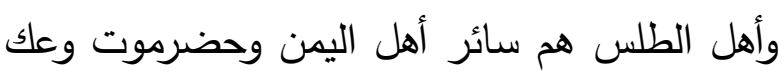
وعجيب وإياد بن نزار (广)، فالوأد إذاً لم يكن موجوداً

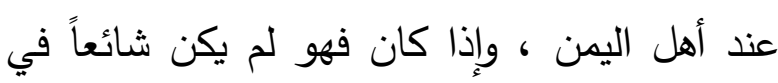

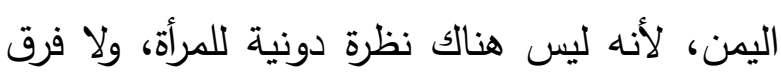

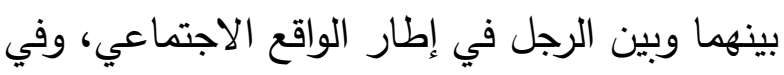

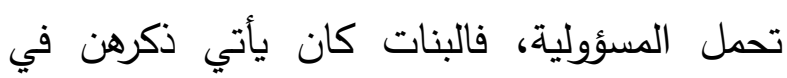

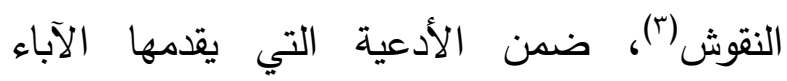

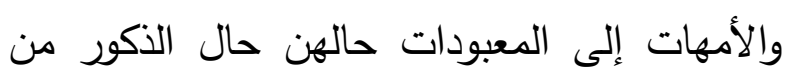

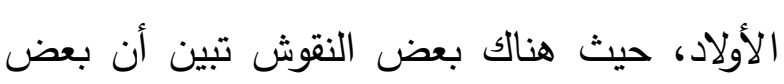
المتعبدين لا يهمه أن يرزقه المعبود ولداً أم بنتاً (๕). هناك من يذهب أن قلة الإشارات الواردة عن الوأد

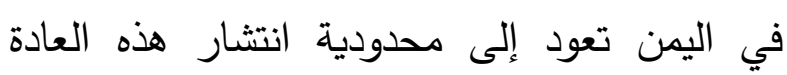

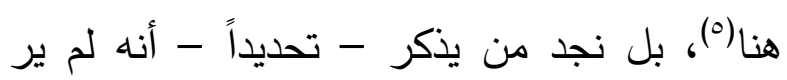

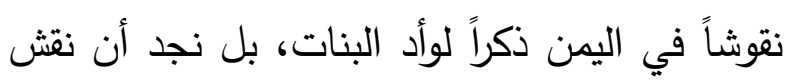

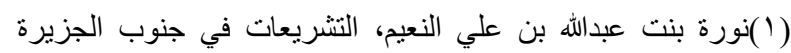

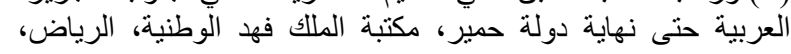

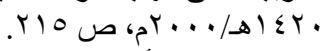

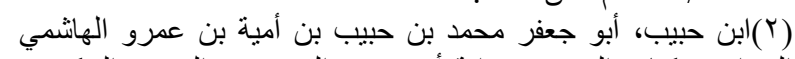

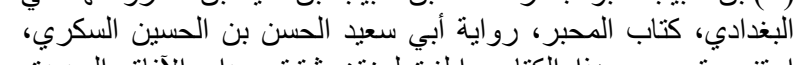
اعتى بتصحيح هذا الكتاب: إيلزة ليختن شتيتر، دار الآفاق الجديدة، اليكرية

(3) RES, 3689 = GL. 1602=Ry491

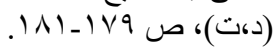

تفيلياً: انظر:

Kitchen, K.A.,The World of Ancient Arabia Series: Documentation for Ancient Arabia, Part 11, Bibliographical Catalogue of Texts, Liverpool University Press, 2000, P.477.

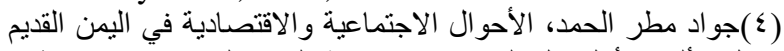

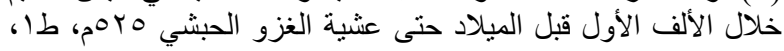

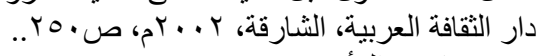

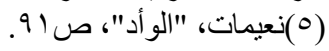


رهطاً من الرجال يجتمعون على امرأة، يعيشون

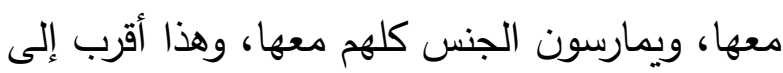
ما يسمى بالدعارة، وليس بالزواج المعروف عند وهند

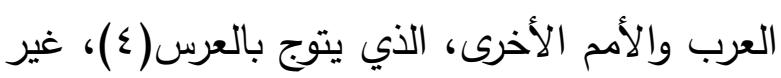
أن الباحث هنا يعترض على ما ذهب إليه بيتر فيما

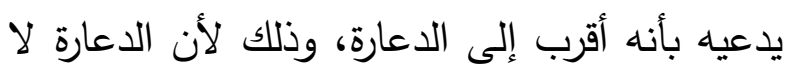

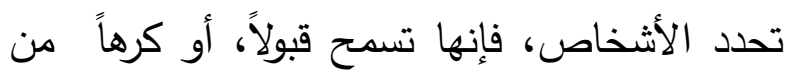
سيدها - كمثل البغاء - ولكن الرهط هنا محدد بأنه دون العشرة وأنها حينما استدعتهم جاءوها، فبالتالي لهاء هو نوع من أنواع الزواج، كما سماه وعرَّفه البخاري،

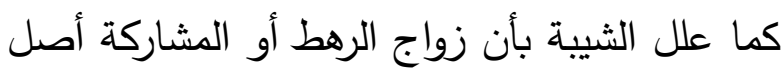

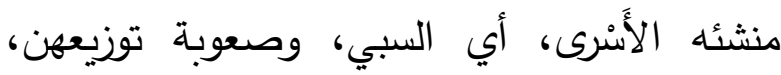
حيث تُعطَى فتاة من السبايا يشتركون فيها، وقد الد يكون سببه التكلفات والصعوبات المالية في الزواج، لئرناه ومن ثم يشترك الإخوة في زوجة واحدة، أو قد يكون سببه الوراثة، إذ يرث أكبر الأولاد زوجة أبيهم

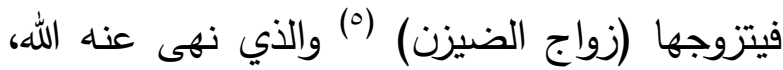
سبحانه وتعالى (†). هناك من يذكر أن زواج المشاركة لم يكن معروفاً على الرغم من مناداة بعض الدارسين بوجوده

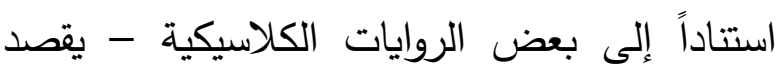
رواية سترابو - ورواية البخاري حول الزواج عند العرب قبل الإسلام، وإستتاداً إلى بعض الدراسات

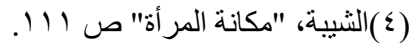

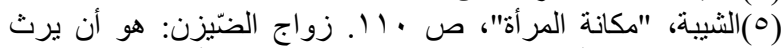

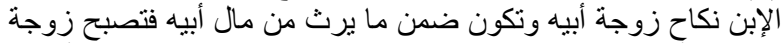

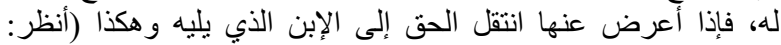

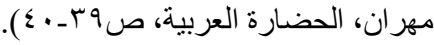

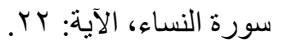

حتى رآها - فخيل إليه أن الأمر كذلك عند القوم.

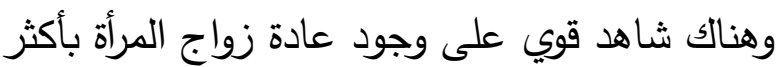
من رجل لدى عرب الثمال(')، نسوقه من صحيح

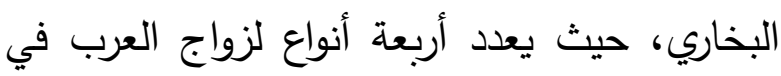

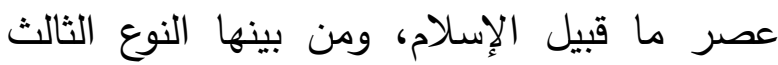

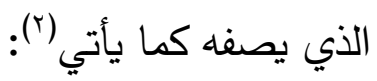

"... يجتمع الرهط ما دون العشرة

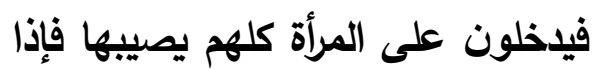
حملت ووضعت ومرت ليال بعد أن تضع حملها أرسلت فلم يستطع رجل منهم أن يمتنع حتى يجتمعوا عندها، تقول لهم: قد عرفتم الأي كان من أمركم وقت ولات فهو ابنك يا فلان، تسمي من أحبت باسمه فيلحق به وله

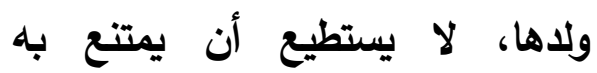

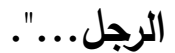

يرى الأمير بيتر(r) أن هذا الثاهد واضح تماماً

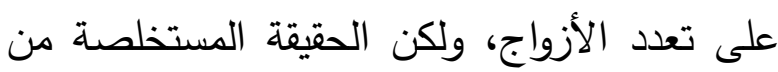
النص بأنه لا يذكر زواجاً، ولا زوجة، بل بل يذكر ولئه

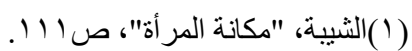

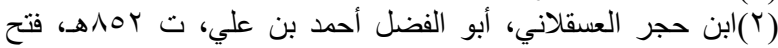

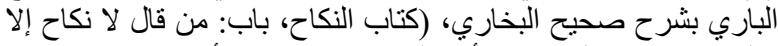

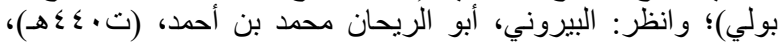

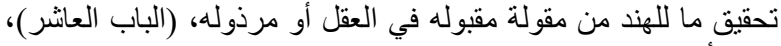

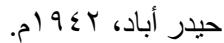

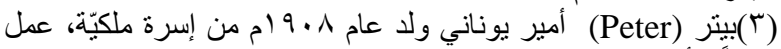

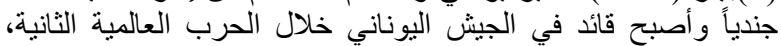

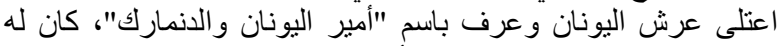

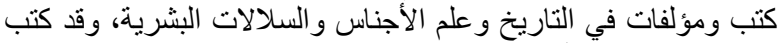
عن حضارة وثقافة ألتبت، وله مؤلف عن: Polyandry، Peter, Prince of Greece, A Study of Polyandrys the Hague, Mouton (أنظر : (Wikipedia: Prince Peter of Greece) 
من النقوش السبئية التي تعود إلى القرنين الثالث والرابع الميلاديين وهي كالتالي:

Ja610, 10-12=Ma نقش (سبئي)

$:^{\left({ }^{\circ}\right)} \mathrm{MB208}$

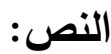

$$
\begin{aligned}
& \text { ]ن ش أ ك ر ب إى أ م ن / } \\
& \text { هـ ح ب/ م ل ك/ س ب أ/ و } \\
& \text { ذ ر ى د ن ن/ ب ن/ أ ل ش ر }
\end{aligned}
$$

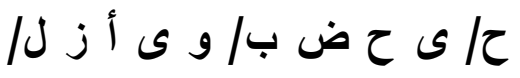

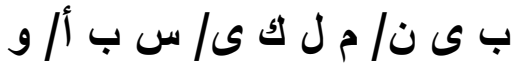

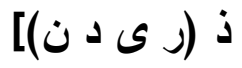

"... نشأ كرب يأمن يهر حب،

ملك سبأ وذو ربدان، ابن ال

شرح يحضب، ويازل بين، ملكي

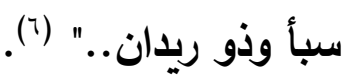

يتبين من النص السابق أن الملك نشأ كرب يأمن

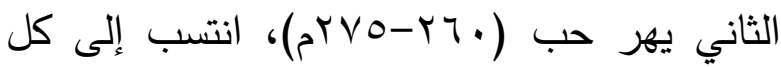

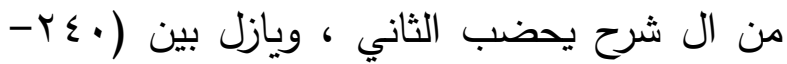

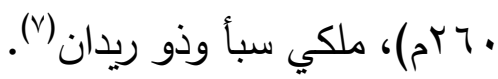

Minaern, (in) Altorientaliche Forschhongen, 11, 1898, P.810.

(5) Kitchen, Documentation for Part 11, p.284;

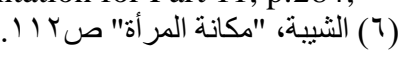

Jamme, A. W. F., Sabaean Inscriptions from Mahram Bilqis (Marib), Baltimore, 1962, PP. 107-108.

(7) Kitchen, K.A., The World of ancient Arabia series: Documentation for Ancient Arabia, Part 1, Chronological Frame Work \& Historical Sources, Liverpool University Press, 1994, P.P. 13-14,19,245.
الاجتماعية الحديثة لبعض الفئات في جنوب شبه الجزيرة العربية، الدالة على ممارسة هذا النوع من العلاقات الاجتماعية في جنوب شبه الجزيرة العربية في الفترة السابقة للإسلام ('). اعتمد موللر (Muller) على مجموعة من النقوش السبئية للدلالة على وجود مثل هذه العادات(r)، وهو مولري زواج المشاركة، وثمة عدد من النقوش السبئية للدلالة على هذا الزواج وهي تظهر فيها لفظة "أ ث ت" وتدل على مفرد المؤنث وقد أتصل بها ضمير المذكر في صيغتي المثنى"ه م ى" أو صيغة ألجمع "ه م م و فالصيغة تعني إما "زوجاها" أو "أزواجهما"(r) - (")

في حقيقة الأمر، هنالك صدى لرواية سترابو في النقوش اليمنية والتي تمثل نوع من أنواع النكاح التي مارسها المجتمع العربي القديم ألا وهو نكاح المشاركة القديمة، وذلك بشيوع تعدد الأزواج هنا (Frateranl Polyandry) بالبحث عن دراسات تؤيد ما ذهب إليه سترابو، وعلى وجه الخصوص، بأن فينكلر (Winchler) يعتقد تأكيداً بوجود زواج امرأة واحدة من عدد من الرجال(๕)، ومنها على سبيل المثال، لا الحصرعدد

(1) Ryckmans, J., "A Three Generation Matrilineal Genalogy in a Hassean Inscriptions: Matrilineal Ancestry in Pre-Islamic Arabia", (in) Bahrain Through the Ages, The Archaeology, Ed. By Al-Khalifa, H.A. and Rice, M., London, KPILtd., 1986, P.409.

(2) Muller, W.W., Polyandry: "Sabaische Text zur Polyandric", (in), NESE, 2, 1974.

$$
\text { (r) الثيبة، "مكانة المر أة" صك ال. }
$$

(4) Winchler, H., Die Polyandrie Bei Den 
ك ل ن/هـ ق ن ى و/ أ ل م ق

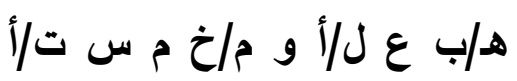
ص ل م ناو ص ل م ت ن ن/ذ

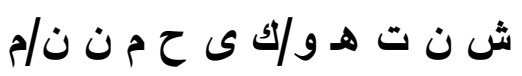
ق م هـ و/ب ك ناى ق ن نى ن ن

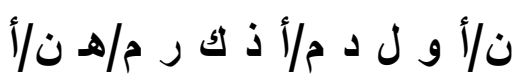
ن/و ح م د و/م ق م/أ ل م ق د د ماه

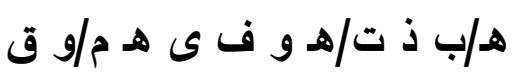

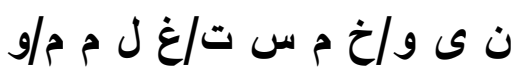

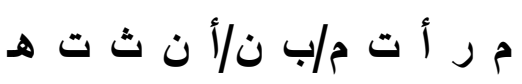
م/ش ن ف ن س رال و ف ى ه/و و ف ى م/ب ن نى هـ م و/ ن

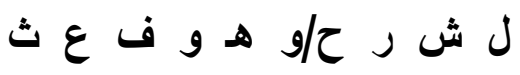
ت/و و هـ ب ع ث ثل/و و د د د أ

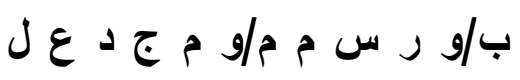

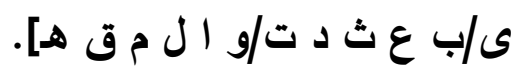

الترجمة: - - (الت

يشير النص إلى أن رجلين أحدهما يدعى مشنوم (مشنوء) والآخر بيت (ربيبم) من بني راسم (رسام)

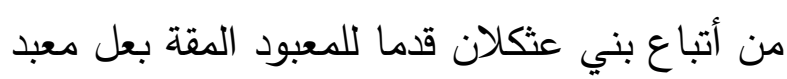

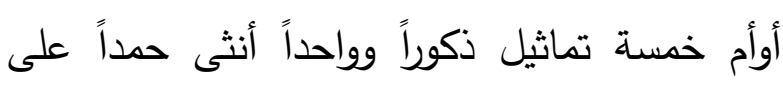
تحقيق رغبتهم في أرزاقهم خمسة من الأبناء وابنة

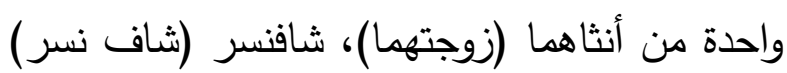

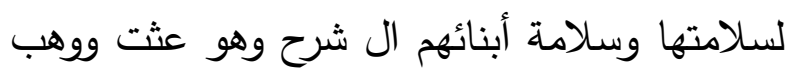
عثت ووداب ورشم ومجد على بحق عثتر وإلمقه (v).

(Y) (Y) سف محمد عبدالله، أوراق في تاريخ اليمن و آثاره، بحوث ومقالات، طب،
Ja 594, 8-9=Ma نقش (سبئي) - r (')MB115

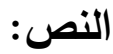

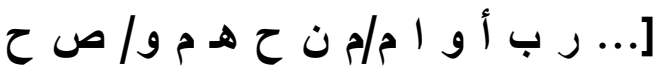

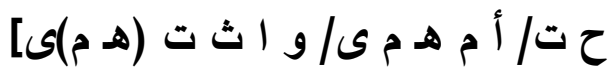
المعنى:

"... أن يمنحها الصحة وأن يمنح أم همي، وإنثهمي، وإبنتهمي..." (؟). أن صاحبي النقش يدعوان المقه (رب أوام) أن

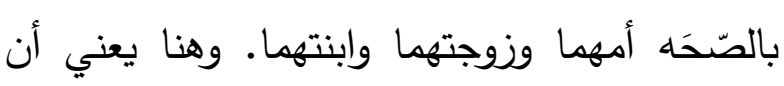
الأخوين(اندثر اسميهما في بداية النقش) كانت لهما ولها أم واحدة وزوجة واحدة وابنتان ويشتركان فيهما"(َ)،

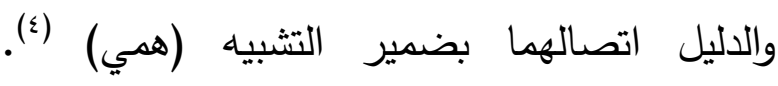
ويلاحظ أن الأسماء متصلة بضمير المثنى، أي أن الن النيل المعنى يحدد: أم الإثنين، وزوجة الإثنين (०). r - في نقش (سبئي) عثر عليه في مدينة مأرب ونثره موللر (Muller) (")

$$
\text { النص: }
$$

(1) Kitchen Documentation, Part II, P. 282.

(2) Jamme, Sabaean Inscriptions, P.98,

PL, 8; Muller, W.W., "Sabaische Texte zur Polyandrie", NESE, Vol.2, 1974, S. 132.

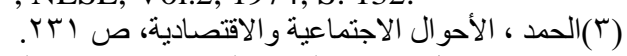

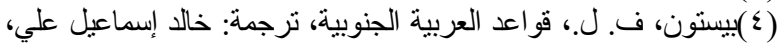

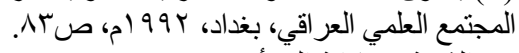

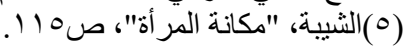

(6) Muller, W.W., "Epigraphische Nachles aus Haz", NESE, vol.1, Wiesbaden, 1972, SS. 75-

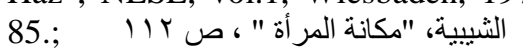


؛ - نقش (سبئي) 247 J) Ja738=Ma MB

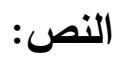

] ح حم د/و أ خ ى هـ و/م ح م

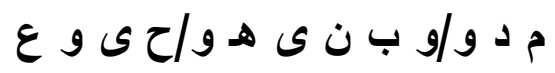

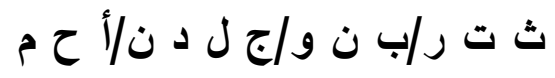

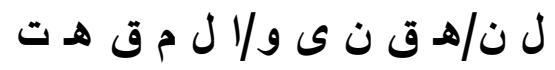

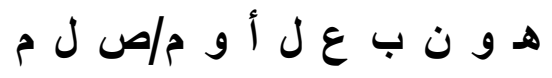

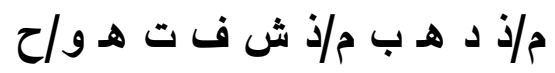

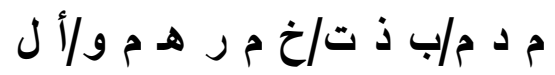

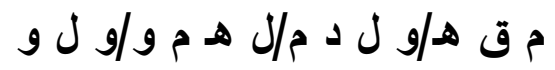

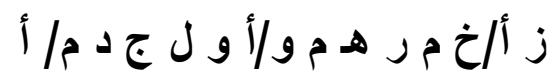

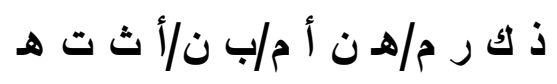

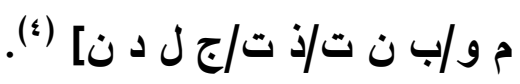

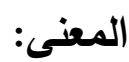
"يحمد وأخاه محمودم وابنه حيوعثتر من بني الجالدان الحملادية قدما للمعبود إلمقه ثهون بعل أوام، تمثالاً برونزياً تعبيراً أو حمداً عن شكرهم على رزقهم بولا من زوجتهم التي من بني

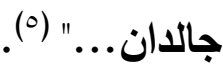

ثم يتبع ذلك الدعاء بأن يرزقهم المعبود أبناء ذكوراً أصحاء من بعد من زوجتهم بنت ذات جالدان.

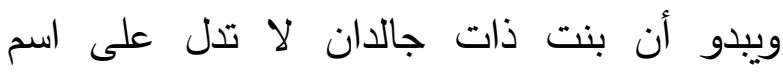
الزوجة، وإنما على أنها امرأة لا تتنمي إلى العشيرة

(3) Kitchen, Documentation, Part II, P.295

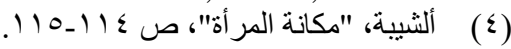

(5) Jamme, Sabaecan Inscriptions, PP.214-215; Muller, NESE, Vol.2, 1974, S.132.
يتبين من محتوى النقش عن تعدد الأزواج، فهناك

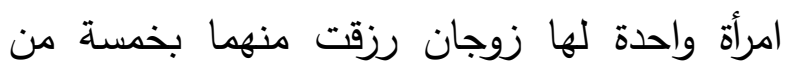

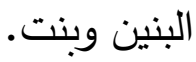
وهناك من يستتتج أن في هذا النقش دلالتان هما'(')

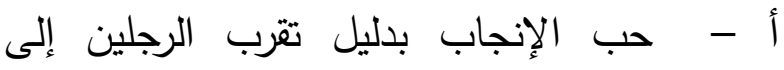

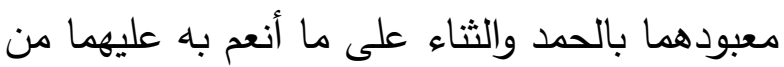

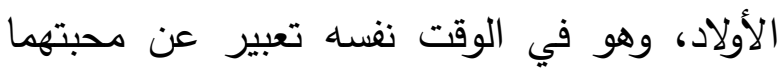

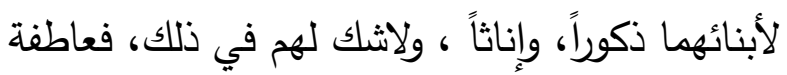

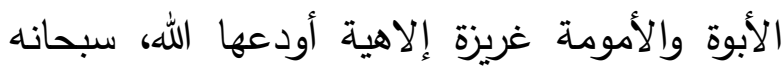
وتعالى، في كل البشر، بل حتى في الحيوانات والطيور • وتعطى، ب - وفي إشارة إلى أن كل من الولد والبنت كان

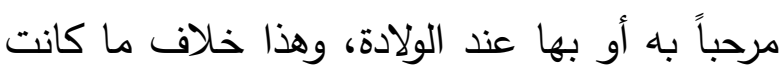
عليه بعض المجتمعات العربية في عصر ما قبل الإسلام، والتي كانت تفضل الابن على البنت، وبخاصة في المجتمعات القبلية. لقد حرص أهل اليمن القديم على أن البنين من

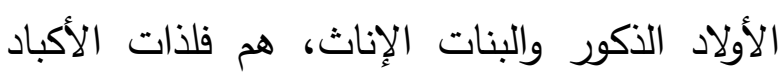

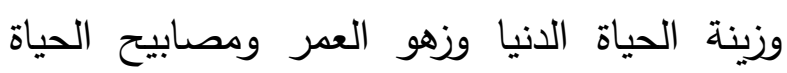
المضيئة التي لا تتطفئ، وهم أعز وأغلى ما في

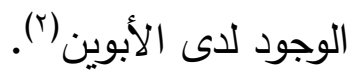

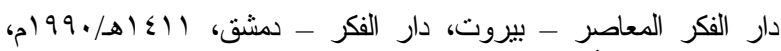

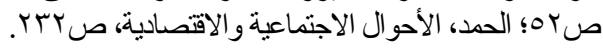

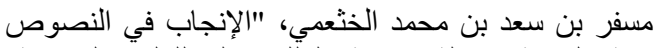

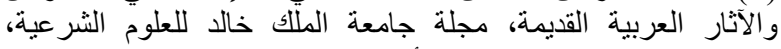

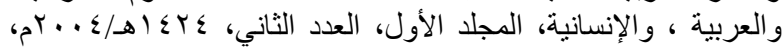

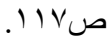

محمد سعد عبده القحطاني، "تقاتمات بنين وبنات قرابين

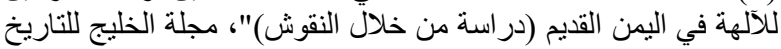

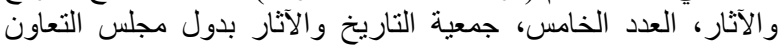

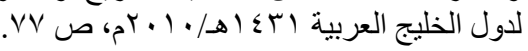




$$
\text { "نكاح (زواج) المشاركة في اليمن القديم }
$$

\section{وابنهما"(£)}

يتبين من محتوى النقش أن ثلاثة رجال (ربما أخوة) كان لهم زوجة واحدة رزقت بولد(*)، وفي نهاية

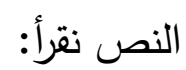

$$
\begin{aligned}
& \text { ].... } \\
& \text { و ر ن/ب ك ل و ن م/و ل هـ ف } \\
& \text { ر ن ن/أ ث ت هـ م و/ ب ن هـ م } \\
& \text { و/عدى د/م ح ر م ن/و لح مد د } \\
& \text { ن ن/م ق م/ال م ق هـ و...] }
\end{aligned}
$$

وفيه يتأكد أنهم ثلاثة رجال وزوجتهم الوحيدة وإبنهم الذين رزقوا با منها (؟) يقودون معهم ثورين إلى

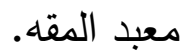

RES4188=Vienna

\section{$:^{(v)} 664, \&$ SE3}

نستتج من محتوى هذا النقش أن ثلاثة من الرجال

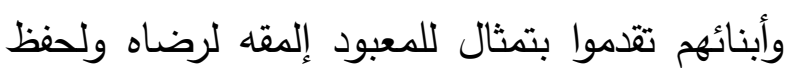
سلامتهم وسلامة زوجتهم وأولادهم (^)، ويذكر الثيبة أن هذا النقش قديم معروف ويحمل الرقم (r) في

(4) Jamme, Sabaean Inscriptions, PP.174175, PL.19; Beeston, A.F.L., "Addenda" to A.K. Irvine Homicide in Pre-Islamic South Arabia", BSOAS, 30, 1967, P.P.284-286, 291$293 ;. . . . . . . . . . . . ., \quad$ "Notes on Old South Arabian Lexicography, XII, Mus, Vol.94, 1981, PP.64-65.

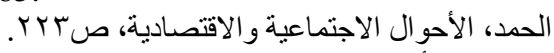

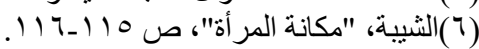

(7)Kitcchen, Documentation, Part II, P.531.

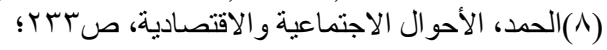

Hofner, M., Die Die Sabaischen Inschriften der Sudarabischen Expedition in Kunschistorichen Museum in Wien (1), WZKM, Vol.40, 1933, S.136; Muller NESE, Vol.2, 1974, SS.132-133.
أو القبيلة نفسها(').

• - نقش (سبئي)

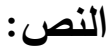

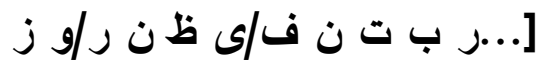

ى د م/أ و ل ط/و أ س ع د/أ ك

ف/و ب ن هـ م و/ع ب د أ و

م/ب ن و/ع ب ل م/و ق ت ر

ن/أ و ت ن/هـ ق ن ى و وام ر أ

هـ م و (/ ) أل م ق هـ ب ع ل

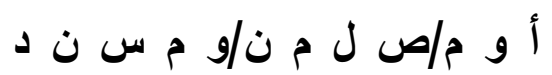

م/ص ر فـ م/و م د/ل ت هـ م

ى/ع ص ى م/و ص ل م م/ذ ذ

هـ ب م/ل ق ب ل ى /ذ و ل د/ ل

هـ م و/ذ ت ب ر م/و ش ف ت

و/ا ل م ق هـ و/ك م هـ م و/ى ل

د ن/ل هـ م و/ب ن م/و ى ح ى

و ن/ف ى ه ق ن ن ى ن

$$
\text { (r) }[\ldots / \dot{0}
$$

هذا النقش ينص على أن ثلاثة رجال هم: "رب تتف يظفر ، وزايدم أولط، وأسعد أكف، وابنهم، عبد أوام دن بني عابلوم (عبال) وقتران أوتان يقدمون للمعبود إلمقه بعل أوام تمثالاً ذهبياً منقوشاً وتمثالاً فضياً لأنه رزقهم بولا يحفظ سلامته، من زوجتهم

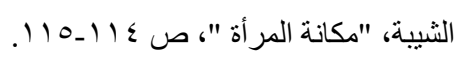

$$
\text { الثيبية، "مكانة المر أة"، ص } 110 \text { ـ 17 11 . }
$$




\section{$:^{(\xi)} 1583 ;$ Ry 375 6-8}

يذكر هذا النقش المعبود المقه الذي وعد صاحبي،

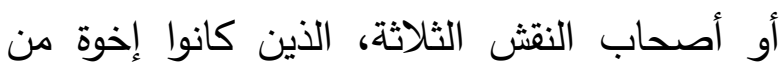
قبيلة بني رحبان بأن يرزقهما، أو يرزقهم بطفل أو الو

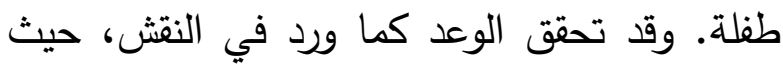

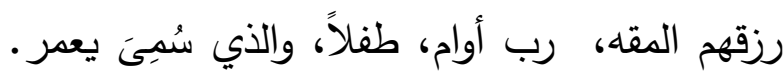

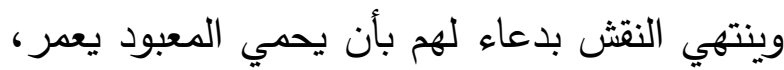

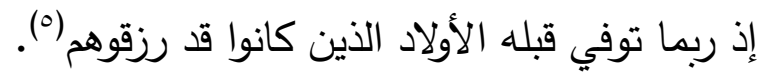

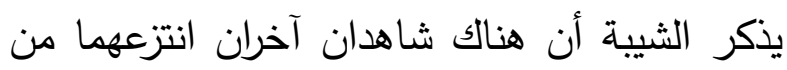

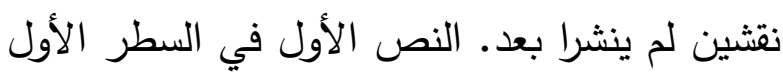

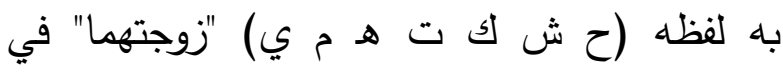
صيغة المثنى، أي زوجة كليهما. أما النص الثاني

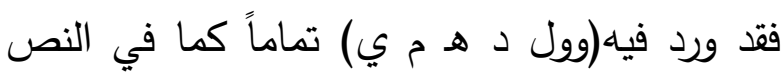
Ja669 السالف الذكر (ㄱ). مما سبق، يتضح، بلا شك، أن المرأة اليمنية كانت تتزوج بأكثر من رجل، كما أن أهل اليمن القديم بلدي كانوا يفضلون الزواج من بنات قبيلتهه، كما أن معظم الذين كانت لهم زوجة واحدة إما أن يكونوا أخوة، أو من قبيلة واحدة، حتى يبقى انتساب الأبناء

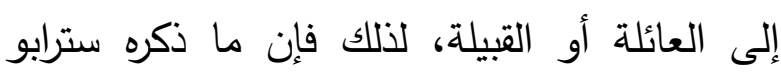
من:"أن الزاني هو الذي يكون من قوم آخرين" (Vال،

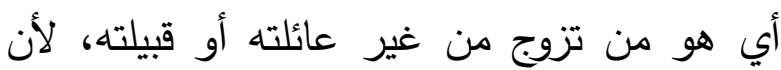
الأولاد سوف ينتسبون إلى قبيلة أمهم (^).

(4)Kitchen, Documentation, Part II, P. 58.

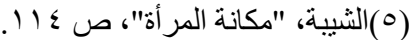

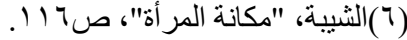

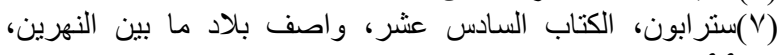
ص99 صنو (^) الحمد، الأحو ال الاجتماعية و الاقتصادية، صهب
بعثة التتيب عن آثار جنوب الجزيرة (Sudarabischen Expedition) أعلاه - لا يختلف موضوعه عن سابقيه وما بعده، ولكن الحديث في هذا النقش يشير إلى معبد

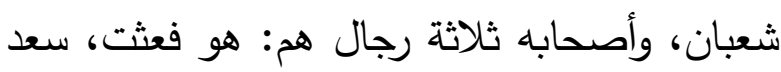

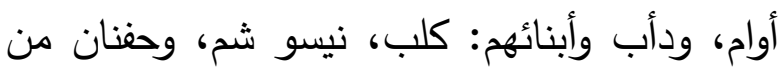
عشيرة مرفدم من قبيلة تشقم، حيث يتقدم هؤلاء

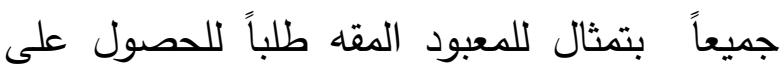
رضاه وحفظ سلامتهم وسلامة زوجتهم وأولادهم،

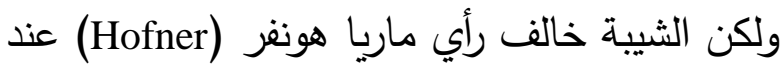
ترجمتها للنقش، لأنها كانت تستبعد تعدد الأزواج عند اليمنيين القدماء (').

RES5102, Ry354- نقش (سبئي) - V (广) 373; al-Azm 8 تعرض هذا النقش إلى التلف من بدايته ونهايته، ولكن بعد قراءته وترجمته نفهم أن وعدا للمعبود ألمقه لإثثين أو ثلاثة من الرجال أصحاب النقش، وند وهم إخوة من بني رحبان؛ أن يرزقهم بطفل ذكر أو الو تلاته بنت من زوجتهم ، ورزقهم أصحاب النقش، غلاماً

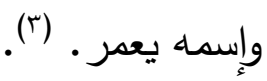

CIAS 2019 [ 39.11/05, نقش (سبئي) - ن : No.3]AM104=NAM

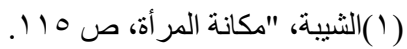
(2)Kitchen Documentation, Part II, P.604, Bron, F. Semitica 24, 1974, 82,

(T) الحمد، الأحو ال الاجتماعية والاقتصادية، ص سبr؛

Ryckmans, G.; "Inscriptions Sud- Arabes.

Huitieme Serie", Mus, Vol.62, 1949, SS.68-69. 
وعليه، فإن النقوش السابقة تشير إلى نوع من

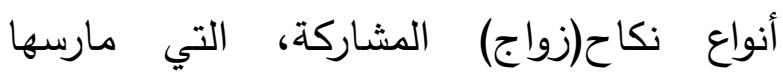

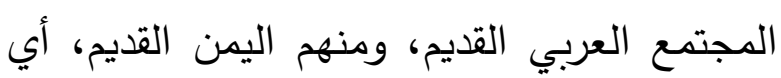

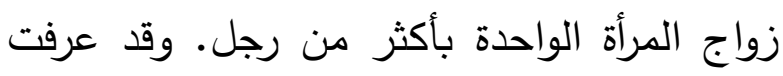

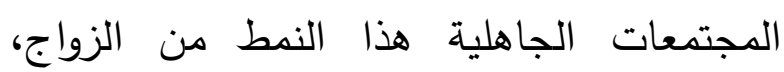

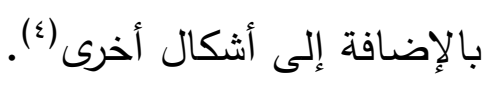

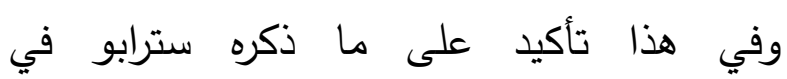

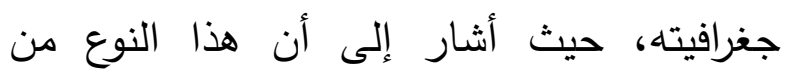
الزواج كان معروفاً في جنوب شبه الجزيرة

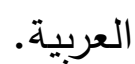

لقد ذكرت المصادر العربية الإسلامية، فضلاً

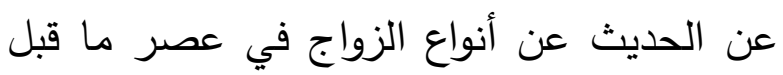

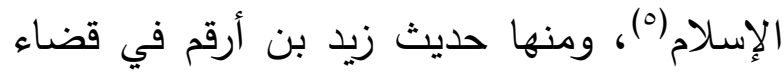
علي بن أبي طالب رضي الله عنه، في نسب

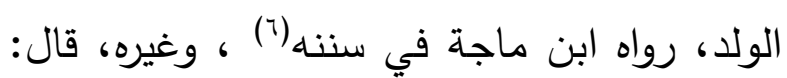

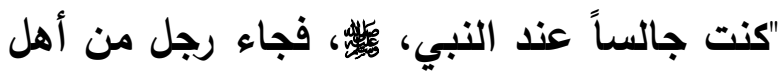
اليمن، فقال أن ثلاثة نفر من أهل اليمن أنواء

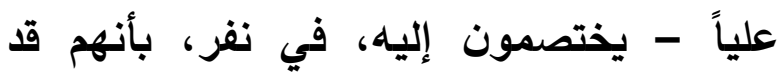

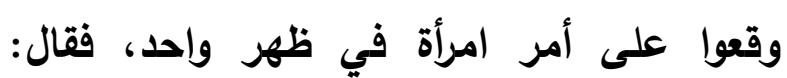
لاثنتين طيبا بالولد لهذا فقالا: لا، ثم لاثنين: طيبا للولد هذا، فقال: لا، فقال: أنتم شركاء

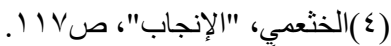

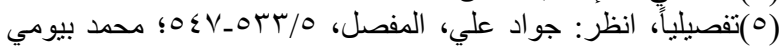

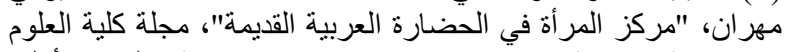

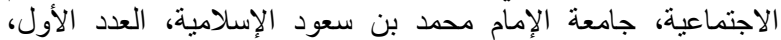

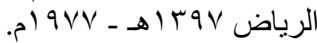

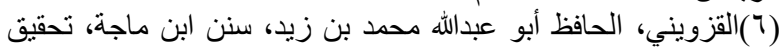

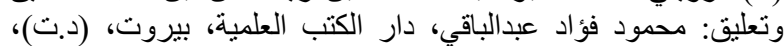

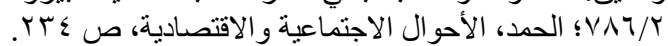

هناك نص قانوني اجتماعي لمدينة مطرة(')، وهو النقش Qutra (MAFRAY) يحتوي على ثلاثة أنظمة قانونية اجتماعية(؟)، ويخص البحث التتظيم الثاني منها، وهو: "لا يحق شرعاً زواج بنات مدينة مطرة من من مان

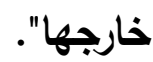

يتبين من النص السابق بأنه يمنع زواج بنات مدينة

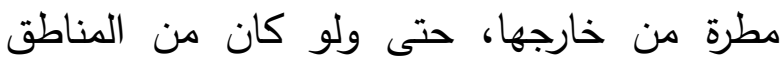
القريبة منها، بل يكون زواجهن من داخل المدينة

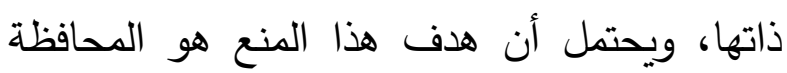

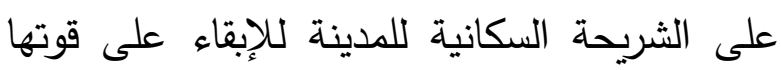

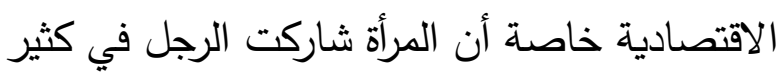

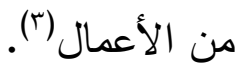
هذا، فإن تعدد الأزواج كان نوعاً ما شائعاً بينهم،

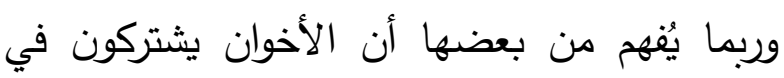
زوجة واحدة، ويرزقون أبناء وبنات مشتركين.

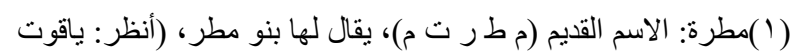

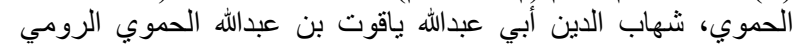

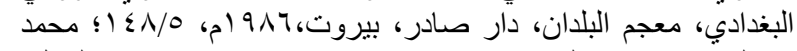

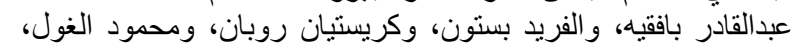

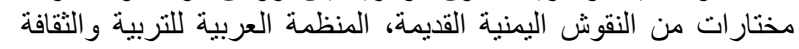

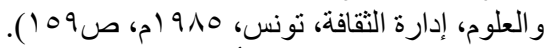

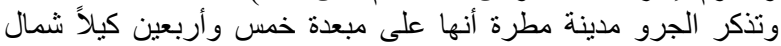

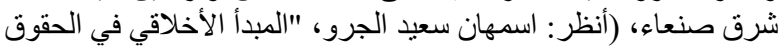

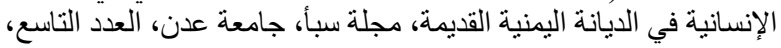

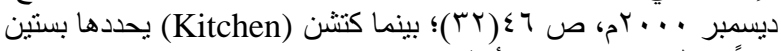

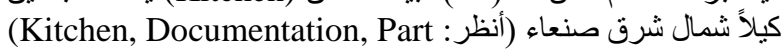
II, P.448)

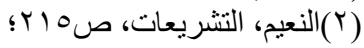
Robin, Ch., Mission Archeologique et Epigrphique Francasis auYemen du Nord, (en Automn: 1978), (RAIBL: Paris, Editions Klincksieck, 1979, PP. 185-190; Fig.3.

(r) (r) النعيم، التشريعات، ص.37) 
ودخولهم فيه، على الرغم من أن حديث زيد بن

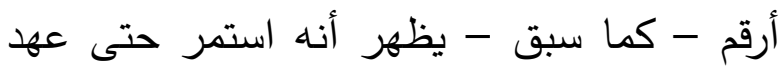

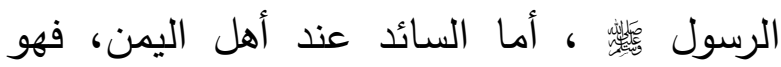
زواج البعولة، أي زواج المرأة من رجل واحد، المال

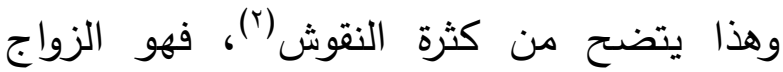

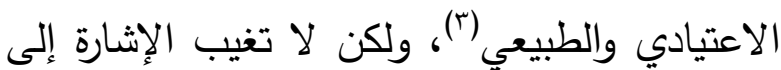
تعدد الزوجات، كما في نقش يعود إلى الفترة

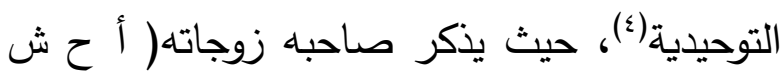

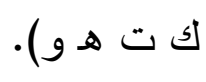

\section{ABBREVIATIONS الاختصارات}

1. BSOAS = Bulletin of the School of Orientation and African Studies, London.

2. $\mathrm{GL}=$ Inschriften der Sammlung E. glaser.

3. Ja = Jamme, A., Sabaean Iscription from Mahram Biliqis (Marib), Publications, American Foundation for the Study of Man, III, Baltimore; Johns Hopkins Press, 1962.

4. Mus $=$ Le Museon, Louvain.

5. $\mathrm{NESE}=$ Nene Ephemeris fur Semitische Epigraphic.

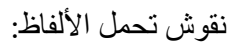 إمر أنه (أث ت ت هـ و) ، أنظر :}

Ja 655=Ma MB 253; Kitchen, Documentation, Pat II, P.288; CIH 544/1=Academic II=Louvre AO 4973; Kitchen, Documentation, Part II, P.124.

$$
\text { زوجته (ح ش ك ت هـ )، أنظر: RES 4109, 3-4 }
$$

RES4109, 3-4 = Aden $=\mathrm{Ja}$ 117; Kitchen, Documentation, Part II, P.524; CIH 543=GL 394+395; Kitchen, Documentation, Part II, P.124.

$$
\text { CIH6/1 =GL7= Cruttenden }
$$$$
\text { 3(=RES2637C)=Fresnel 3=Halevy 3=RWI; }
$$

Kitchen, Documentation, Part II, P.70.

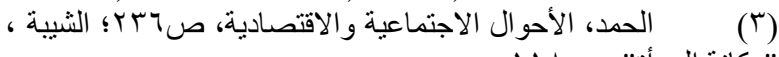

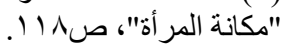
النقش (السبئي) 1 النئي
متثاكسون، أني أقرع بينكم، فمن قرع له فله الولا، وعليه لصاحبه ثلث الاية فاقرع بينهم فجعل لمن قرع لله، فضحك الرسول،

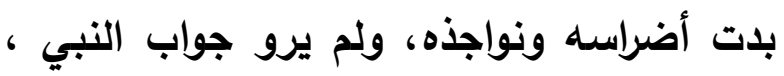

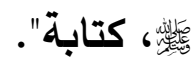
هناك من يتساءل - ومععه الباحث - ولما كان اشتراك أكثر من أب في مجموعة من الأبناء، لتهاءل كيف تكون هذه الشراكة؟ مَنْ من الآباء يقوم على رعاية الأبناء وإعالتهم؟ ومن الذي يقوم بتزويجهج وإلى أي الآباء ينسبون؟ ولمن من الآباء تكون خدمة الأبناء؟ أسئلة تبدو محيرة، الابهاء

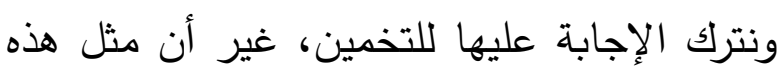

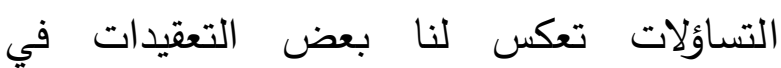
المجتمعات العربية القديمة ('). مما سبق، هناك من بذكر - ويتفق معه الباحث

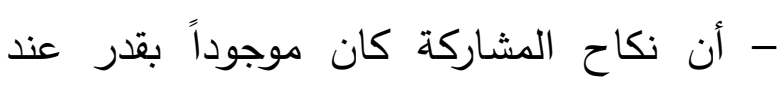

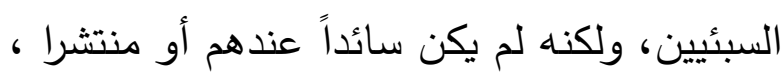

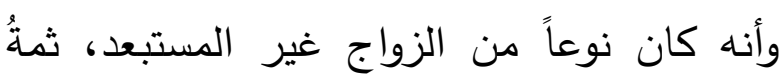

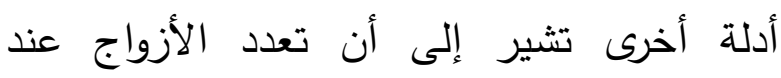

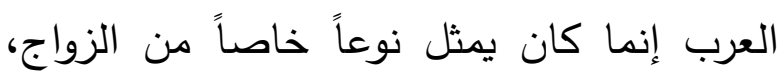
ولم يكن في يوم من الأيام هو الزواج السائد، ولكن من غير المعروف، حتى الآن، في أي وسط كان يحدث، وما نسبة حدوثه الحقيقية، بالإضافة إلى أنه ليس ثمة معلومات وافية متى دمان كانت بدايته؟ ولابد من أنه انتهى بظهور الإسهله لئه 
7- النويري، شهاب الدين أحمد بن عبدالوهاب،

نهاية الأرب في فنون الأدب، القاهرة، بـ 9 ام. ب - المترجمة (المعربة):

- V

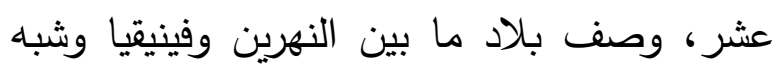

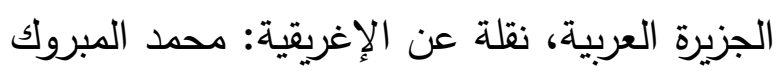

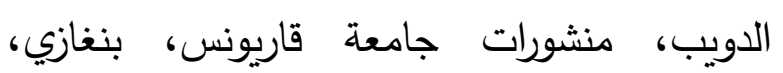
.

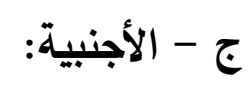

8-Jamme, A. W. F., Sabaean Inscriptions from Mahram Bilqis (Marib), Baltimore, 1962.

9-Kitchen K. A., the World of Ancient Arabia series: Documentation for Ancient Arabia, Part 1, Chronological Framework \& Historical Sources, Liverpool University Press, 1994.

10,The World of Ancient Arabia Series: documentation for Ancient Arabia, Part 11, Bibliographical Catalogue of Texts, Liverpool Univ-ersity Press, 2000.

11-Strabo, The Geography of Strabo, Trans by: H.L. Jones, XVI, London, 1966.

$$
\text { ثأ - أنياً: المراجع: }
$$

Y T- السيد سابق، فقه السنة، طV، دار الكتاب
6. RES $=$ Repertoire d' Epigraphie Semitique, 1-VIII, Paris, 1900-1968 (General ed. J-B. Chabot; V-VIII, ed. G. Ryckmans; VIII, ed. J. Pirenne).

7. Ry = Inschriften, die von G. Ryckmans Publiziert Wurden.

8. WZKM = Wiener Zeitschrift fur die Kunde des Morgenlandes, Vienna.

قائمة المصادر المراجع والدوريات أولاًا: المصادر: أ - المصادر العربية: المداد: المباد

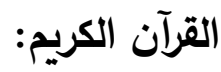
1 - ابن حبيب، أبو جعفر محمد بن حبيب بن

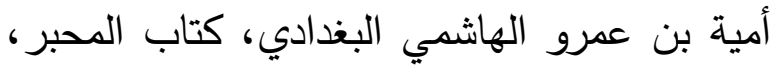
رواية أبي سعيد الحسن بن الحسين السكري، اعتنى

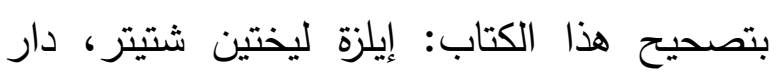
الآفاق الجديدة، (د.ت).

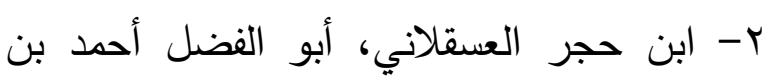
علي، فتح الباري بشرح صحيح البخاري، (كتاب النكاح، باب: من قال لا نكاح إلاًّ بولي).

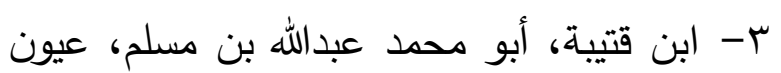

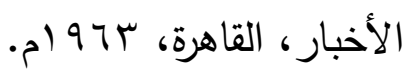

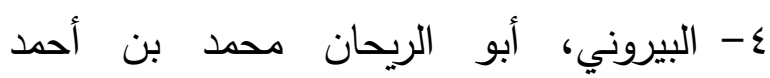

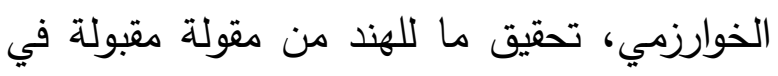

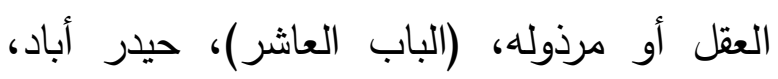
$.019 \leqslant r$ ه- القزويني، الحافظ أبو عبدالله محمد بن زيد، سنن ابن ماجة، الجزء الثاني، تحقيق وتعليق:

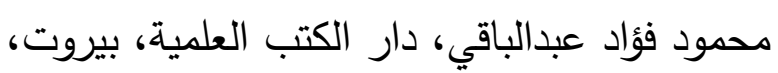
(م) (د) (د) 
دولة حمير، مكتبة الملك فهد الوطنية،

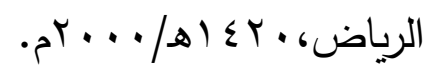

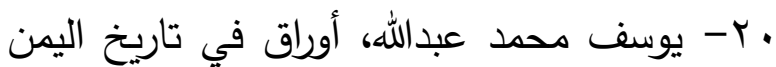

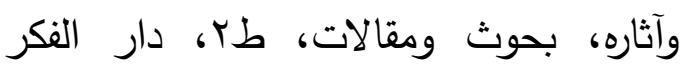

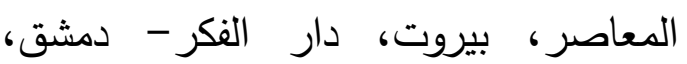

$$
\begin{aligned}
& .0199 . / 81 \leq 11 \\
& \text { ب - المترجمة (المعربة) }
\end{aligned}
$$

ا צ- بيستون، ف. ل. ، قواعد العربية الجنوبية،

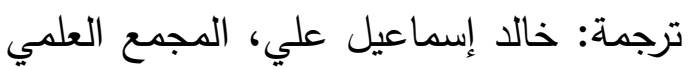

$$
\begin{aligned}
& \text { العراقي، بغداد، ب99 ام. } 9 \text { ام. } \\
& \text { ج - الأجنبية: }
\end{aligned}
$$

22- Encyclopaedia Britannica.

23- Hartmann, M., der Islamische Orient, Bd, ii. Die Arab-ische frage, Leipzie, 1909.

24- Muller, W. W., Neue Ephemeris fur Semitiche Epigraphic, Wiesbaden, 1972.

25- Robertson Smith, W., Kingship and Morriage in Early Arabia, London, 1885.

26- Robin, Ch., Mission Archeologique et Epigraphique Francasis au Yemen du Nord, (en Automn: 1978), CRAIBL: Paris, Editions Klinckieck, 1979.

27- Webster's New Encyclopedic Dictionary New Edition, New York, 1995.

28- Winchler, H., Die Polyondrie Bei Den Minaern, (in) Altorientaliche
العربي، بيروت، 0. (باب الزواج). - (بعرب،

با- جواد علي، المفصل في تاريخ العرب قبل الإسلام، طس، الجزء الخامس، دار العلم للملايين، بيروت، مكتبة النهضة - بغداد، الاسنا، شباط(فبراير) م • 91 ام. ع ا- جواد مطر الحمد، الأحوال الاجتماعية

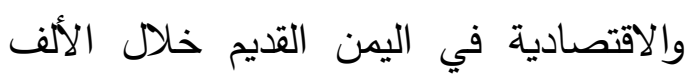
الأول قبل الميلاد حتى عشية الغزو الحبشي، هroم، طا، دار الثقافة العربية، الثارقة، $.5 t \cdot r$

10- عبدالمنعم ماجد، التاريخ السياسي للدولة العربية، القاهرة، لو 97 ام.

17 - محمد بيومي مهران، مصر والثرق الأدنى القديم (V) الحضارة العربية القديمة، المعرفة

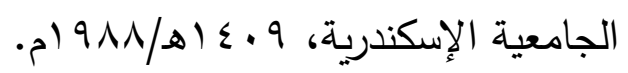
IV وكريستيان، روبان، ومحمود الغول، مختارات

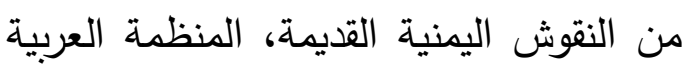

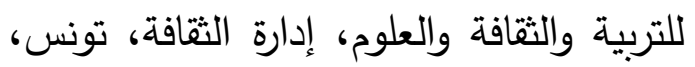
. $) 910$ 11- محمد محمود جمعة، النظم الاجتماعية والسياسية عند قدماء العرب والأمم السامية، القاهرة، 9 9 9 (م. 9 1 - نورة بنت عبدالله بن علي النعيم، التشريعات في جنوب غرب الجزيرة العربية حتى نهاية 
العصور القديمة"، مجلة كلية اللغة العربية والعلوم الاجتماعية، جامعة الإمام محمد بن سعود الإسلامية،

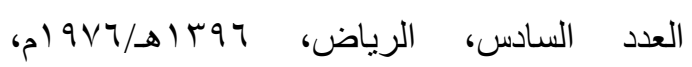

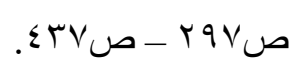
ع الحضارة العربية القديمة"، مجلة كلية العلوم الاجتماعية، جامعة الإمام محمد بن سعود الإسلامية،

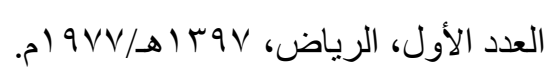
هـ- محد سعد عبده القحطاني، "تقدمات بنين وبنات قرابين للآلهة في اليمن القديم (دراسة من خلال النقوش)"، مجلة الخليج للتاريخ والآثار، العدد الخامس، جمعية التاريخ والآثار بدول مجلس التعاون

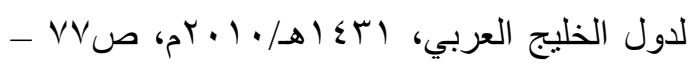
ص ( D

محمد عبودي إبراهيم، "اسنر ابون يتحدث عن حملة أيلوس جاللوس علي بلاد العرب"، مجلة كلية الآداب، المجلد التاسع والثثلاثون، الإسكندرية، العام

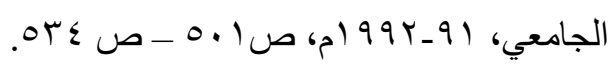

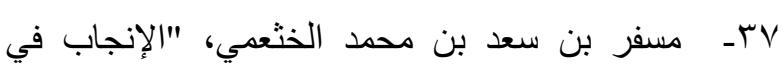
النصوص والآثار العربية القديمة"، مجلة جامعة بنة الملك خالد للعلوم الثرعية، والعربية، والإنسانية،

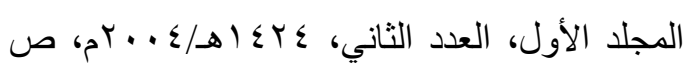

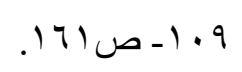

^ץ-ـ هاني أبو الرب، "الوأد عند العرب قبل الإسلام وموقف الإسلام منه"، مجلة در اسات للعلوم الإنسانية والاجتماعية، المجلد بس، العدد ال، الجامعة

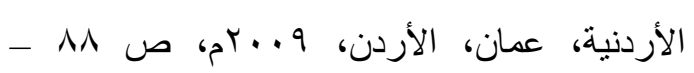

$$
\text { ب - الأجنبية: }
$$

39- Besston, AF.L., "Addenda" to A.K.

\section{Forschongen, 11, 1898.}

ثالثاً: الرسائل العلمية: و ب- نجوى محمد محمد جميل إكرام، "النشاط التجاري عند المجتمعات العربية في شمال غرب شبه الجزيرة العربية في عصر ما قبل الإسلام - در اسة تاريخية حضارية"، قسم الدراسات العليا التاريخية والحضارية، كلية الثريعة والدراسات الإسلامية،

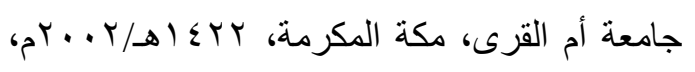

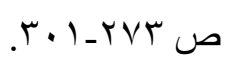

$$
\text { رأ - العربية: الدوريات: }
$$

• r- اسمهان سعيد الجرو، "المبدأ الأخلاقي في الحقوق الإنسانية في الديانة اليمنية القديمة"، مجلة سبأ،

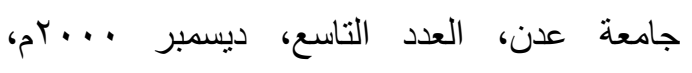

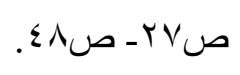
اب- سلامة نعيمات، "الوأد عند العرب قبل الإسلام"،

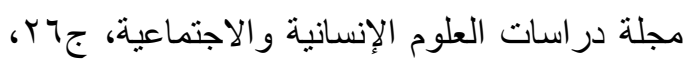

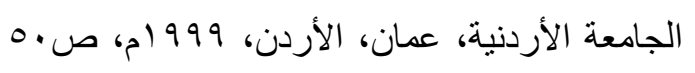

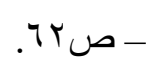
r ب- عبدالله حسن الثيبة، "مكانة المر أة في اليمن القديم"، دراسات في تاريخ الجزيرة العربية وحضارتها، مهداة إلى الأستاذ الدكتور عبدالرحمن بن محمد الطيب الأنصاري بمناسبة بلو غه سن السبعين عاماً،

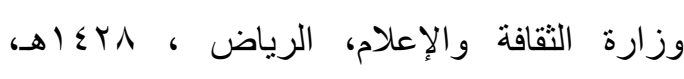

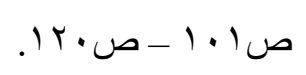

rس- محمد بيومي مهران، "العرب وعلاقاتهم الدولية في

\section{Irvine Homicide in Pre-Islamic}

South Arabia", BSOAS, 30, 1967, 
PP. 280-295.

40"Notes on Old South

Arabian Lexicography, XII, Mus, Vol.94, 1981, PP. 60-75.

41- Hofner, M., Die Sabaischen Inschriften der Sudara-bischen Expedition in Kunchistorichen Museum in Wien (1), WZKM, Vol.40, 1933, SS.1-36.
42- Muller, W.W., "Epigraphische Nachlese aus Haz", NESE, Vol.,1, Wiesbaden, 1972, PP.75-85.

43- Muller, W.W.,"Sabaische Textezur Polyandrie", NESE, Vol.2, Wiesbaden, 1974, PP.125-138.

44- Ryckmans, G.,"Inscriptions SudArabes. Huitieme Serie", Mus, Vol.62, 1949, SS.55-124. 


\title{
Marriage (marriage) participation in old Yemen An analytical study "
}

\author{
Najwa Muhammad Ikram \\ Umm Al Qura University
}

\begin{abstract}
Polyandry Marriage in Arabia Felix. Uncommon form of marriage such as polyandry marriage, were have been known among the Arabs in ancient era. Polyandry was a form of marriage in which a woman was married to several men at the same time.

The paper shed the light on the disagreement between the scholars about this kind of marriage whether it was well-known and, as well as, was widespread, or the opposite. However, the writer, based on several Sabaean Inscription, emphasize that cases of polyandry Marriage have been occurred in Arabia Felix, but it was not a conventional or familiar marriage, as well as rare and limited.
\end{abstract}

